\title{
S100A8 facilitates the migration of colorectal cancer cells through regulating macrophages in the inflammatory microenvironment
}

\author{
HE ZHA $^{1}$, HUI SUN ${ }^{1}$, XUERU LI ${ }^{1}$, LIANG DUAN $^{2}$, AIFANG LI $^{1}$, YUE GU $^{1}$, ZONGYUE ZENG $^{1}$ \\ JIALI ZHAO ${ }^{1}$, JIAQING XIE ${ }^{1}$, SHIMEI YUAN ${ }^{1}$, HUAN LI $^{1}$ and LAN ZHOU ${ }^{1}$ \\ ${ }^{1}$ Key Laboratory of Clinical Diagnosis, Ministry of Education, College of Laboratory Medicine, \\ Chongqing Medical University, Chongqing 400016; ${ }^{2}$ Department of Laboratory Medicine, \\ The Second Affiliated Hospital of Chongqing Medical University, Chongqing 400010, P.R. China
}

Received January 28, 2016; Accepted March 16, 2016

DOI: $10.3892 /$ or.2016.4790

\begin{abstract}
Previous studies have shown that $\mathrm{S} 100$ calcium-binding protein A8 (S100A8) contributes to the survival and migration of colorectal cancer (CRC) cells. However, whether S100A8 participates in the progression and metastasis of CRC via the regulation of macrophages in the tumor inflammatory microenvironment remains unknown. In this study, phorbol myristate acetate (PMA) was used to induce the differentiation of THP-1 monocytes to macrophages. MTT assay, western blot analysis, immunofluorescence staining, semi-quantitative RT-PCR (semi-PCR), quantitative real-time PCR (qPCR), Gaussia luciferase activity assay and ELISA were performed to analyze the roles and molecular mechanisms of S100A8 in the modulation of macrophages. MTT assay, flow cytometric analysis, Hoechst staining, wound healing and Transwell migration assay were used to test the effect of S100A8 on the viability and migration of CRC cells co-cultured with macrophages in the inflammatory microenvironment. We found that THP-1 monocytes were induced by PMA and differentiated to macrophages. S100A8 activated the $\mathrm{NF}-\kappa \mathrm{B}$ pathway in the macrophages and promoted the expression of miR-155 and inflammatory cytokines IL-1 $\beta$ and TNF- $\alpha$ in the inflammatory microenvironment mimicked by lipopolysaccharides (LPS). Furthermore, S100A8 contributed to augment the migration but not the viability of the CRC cells co-cultured with the macrophages in the inflammatory microenvironment. Altogether, our study demonstrated that S100A8 facilitated the migration of CRC cells in the inflammatory microenvironment, and the underlying molecular mechanisms may be partially attributed to the overexpression of miR-155,
\end{abstract}

Correspondence to: Professor Lan Zhou, Key Laboratory of Clinical Diagnosis, Ministry of Education, College of Laboratory Medicine, Chongqing Medical University, Chongqing 400016, P.R. China

E-mail: zhoulan0111@foxmail.com

Key words: S100A8, colorectal cancer, miR-155, inflammatory cytokines, NF- $\mathrm{BB}$, migration
IL-1 $\beta$ and TNF- $\alpha$ through activation of the NF- $\kappa$ B pathway in macrophages.

\section{Introduction}

Colorectal cancer (CRC), for which distant metastasis accounts for the leading cause of cancer mortality, is one of the most malignant gastrointestinal carcinomas worldwide (1). The pathogenesis of CRC is a complex process and involves environmental influences, genetic alterations, and the host immune system and their interactions. The formation of an inflammatory microenvironment also plays a pivotal role in the development of CRC (2). The host microenvironment is comprised of numerous infiltrating immune cell types and resident tumor cells. Among the immune cells, macrophages play an indispensable role. For instance, macrophage infiltration in colon tissue has been observed in both inflammatory bowel disease (IBD) and CRC (4), and the cytokines secreted by macrophages under certain conditions have directly or indirectly stimulated inflammation and tumor progression $(5,6)$. Although great progress has been made, the interactions and the molecular mechanisms between CRC and the inflammatory microenvironment remain unknown.

S100A8 (calgranulin A or S100 calcium-binding protein A8) is a member of the low-molecular calcium binding S100 protein family. It also belongs to the family of damage-associated molecular patterns (DAMPs). Studies have shown that S100A8 plays an important role in regulating tissue inflammation as a ligand of toll-like receptor 4 (TLR4) and/or receptor for advanced glycation end products (RAGE) $(7,8)$. Aberrant expression of S100A8 has been found in different types of tumors including CRC (9) and the accumulation of $\mathrm{S} 100 \mathrm{~A} 8$ positive cells is always located in the invasive margin of colorectal carcinoma (10) which plays a critical role in the tumor microenvironment. Interestingly, mounting evidence indicates that the apical surface of the intestinal epithelium is exposed to lipopolysaccharides (LPS) from the lumen due to intestinal mucosal permeability and bacterial translocation (11). LPS could cause a cascade of inflammatory responses mediated by diverse inflammatory cells that secrete various chemokines and cytokines favoring CRC growth and migration. Nevertheless, little research has been conducted to 
elucidate the effects of S100A8 on modulating the inflammatory response triggered by LPS in the tumor microenvironment.

MicroRNAs (miRNAs) are small non-coding RNAs which function in the post-transcriptional regulation of genes and cellular homeostasis (12). Deregulated miRNA expression has been observed in diverse disorders such as autoimmune diseases, chronic inflammatory pathologies and cancers, including CRC (13). miR-155, an oncogenic miRNA, is identified as a link between inflammation and cancer (14). Previous studies have found that miR-155 expression is induced by proinflammatory mediators, such as TNF- $\alpha$ and LPS (15), and overexpression of miR-155 has been found to elevate inflammatory cytokine production in intestinal myofibroblasts (16) and monocyte/macrophages (17,18). In addition, some studies indicate that the promoter region of pri-miR-155 contains putative NF-kB-binding sites $(19,20)$ and miR-155 upregulation and subsequent molecular events are associated with inflammatory processes such as activation of NF- $\mathrm{KB}(21,22)$. However, the role of S100A8 in the modulation of miR-155 expression in macrophages in the inflammatory microenvironment and its contribution to the development of CRC have not yet been investigated.

In the present study, we mimicked the intestinal inflammatory environment using LPS to investigate the role of S100A8 in the tumor microenvironment. We found that S100A8 markedly promoted miR-155 expression and inflammatory cytokine secretion in the macrophages, which was involved in the activation of the NF- $\mathrm{kB}$ signaling pathway. The results indicate that S100A8 facilitated the migration but not the viability of CRC cells in the tumor microenvironment by conditioned medium (CM) culture or co-culture manner. Our study highlights the significance of S100A8 in the progression of CRC, and may provide an opportunity for the development of targeted therapy for CRC.

\section{Materials and methods}

Reagents and antibodies. Recombinant plasmids pGST-moluc, pGST-moluc-hS100A8 and pNF-кB-luc were kindly provided by Professor T.C. He (The University of Chicago Medical Center, Chicago, IL, USA). Competent bacteria E.coli BL21 were retained in our laboratory. LPS, inhibitor of NF- $\kappa B$ (Bay 11-7082) and phorbol myristate acetate (PMA) were purchased from Sigma-Aldrich (St. Louis, MO, USA). Radio immunoprecipitation assay (RIPA) buffer was obtained from Beyotime (Shanghai, China). Phosphatase inhibitor and protease inhibitor were purchased from Roche Diagnostics GmbH (Mannheim, Germany). Nuclear-cytosol extraction kit was obtained from KeyGen Biotech Co., Ltd. (Nanjing, China). Polyvinylidene difluoride (PVDF) membranes and enhanced chemiluminescence (ECL) kit were both purchased from Millipore Corporation (Billerica, MA, USA). 3-(4,5-Dimethylthiazol-2-yl)-2, 5-diphenyltrazolium bromide (MTT) reagent was obtained from Sigma-Aldrich. Lipofectamine $^{\mathrm{TM}} 2000$ and TRIzol reagents were both obtained from Invitrogen Life Technologies (Carlsbad, CA, USA). Real-time PCR kit and SYBR Premix Ex Taq ${ }^{\mathrm{TM}}$ II were both procured from Takara Bio, Inc. (Dalian, China). Single Luciferase Reporter Assay system was obtained from New England Biolabs, Inc. (NEB; Ipswich, MA, USA).Human IL-1 $\beta$ ELISA kit and human TNF- $\alpha$ ELISA kit were both acquired from ExCell Biology (Shanghai, China). Crystal violet was purchased from Sigma-Aldrich. All antibodies used in this study were as follows: mouse anti-GST monoclonal antibody was obtained from Zoonbio Tech Co., Ltd. (Nanjing, China), mouse anti-S100A8 monoclonal antibody was purchased from Santa Cruz Biotechnology, Inc. (Santa Cruz, CA, USA) and rabbit anti-CD284 (TLR4) polyclonal antibody was acquired from ImmunoWay Biotechnology, Co. (Newark, DE, USA). Rabbit anti-phospho-NF-kB p65 (Ser536) (93H1) antibody was procured from Cell Signaling Technology, Inc. (Boston, MA, USA) and rabbit anti-histone H3.1 monoclonal antibody was obtained from Abmart Inc. (Shanghai, China). Mouse anti- $\beta$-actin monoclonal antibody, goat anti-rabbit IgG and goat anti-mouse $\operatorname{IgG}$ were all purchased from Zhongshan Golden Bridge Biotechnology Co., Ltd. (Beijing, China). Alexa Fluor 488 conjugated goat anti-rabbit IgG was acquired from Beyotime.

Cell lines, cell culture and differentiation. Human monocyte/macrophage (THP-1) cells and human colorectal carcinoma cell lines HCT116 and SW480 were purchased from the American Type Culture Collection (ATCC; Manassas, VA, USA). THP-1 cells were cultured in Roswell Park Memorial Institute (RPMI)-1640 medium and HCT116 and SW480 cells were cultured in Dulbecco's modified Eagle's medium (DMEM) in a controlled atmosphere of $5 \% \mathrm{CO}_{2}$ and $37^{\circ} \mathrm{C}$. All the media were supplemented with $10 \%$ fetal bovine serum (FBS) (Gibco Life Technologies, Carlsbad, CA, USA), $100 \mathrm{U} / \mathrm{ml}$ penicillin and $100 \mu \mathrm{g} / \mathrm{ml}$ streptomycin (both obtained from HyClone, Logan, UT, USA).

Differentiation was achieved by THP-1 cells with PMA $(50 \mathrm{ng} / \mathrm{ml})$. The cells were resuspended at $1 \times 10^{6}$ cells $/ \mathrm{ml}$ and then incubated at $37^{\circ} \mathrm{C}$ for $24 \mathrm{~h}$. The PMA-containing medium was removed and the cells were incubated in fresh medium for another $24 \mathrm{~h}$ to eliminate the effect of PMA, and used for the following experiments.

Preparation and identification of recombinant protein. The preparation of recombinant GST and GST-hS100A8 proteins used in this study was previously described (23). In brief, the pGST-moluc and pGST-moluc-hS100A8 were transformed into BL21 bacteria by calcium chloride transformation. Isopropylthio- $\beta$-D-galactoside was used to induce the expression of GST and GST-hS100A8 proteins. Then the bacteria were collected and sonicated on ice and the supernatant was spun and incubated with glutathione-sepharose 4B beads overnight. Next, GST and GST-hS100A8 on the beads were eluted by elution buffer containing reduced glutathione. Finally, the two proteins were filtered via a $0.22-\mu \mathrm{m}$ membrane and stored at $-80^{\circ} \mathrm{C}$.

The recombinant GST and GST-hS100A8 proteins were subjected to polyacrylamide gel electrophoresis. After electrophoresis, the gel was incubated in Coomassie Brilliant Blue staining solution for $1 \mathrm{~h}$. Then the Coomassie Brilliant Blue elution buffer was used to de-stain the gel until the background turned transparent. All steps were processed on a rotary shaker with a slow speed of revolution.

Western blot analysis. Differentiated THP-1 macrophages treated with and without LPS, GST and GST-hS100A8 or pretreated with Bay 11-7082 $(50 \mathrm{ng} / \mathrm{ml})$ were collected and 
washed with ice-cold PBS three times, and then lysed in ice-cold RIPA buffer containing phosphatase inhibitor and protease inhibitor. Nuclear and cytoplasmic proteins were extracted using a nuclear-cytosol extraction kit according to the manufacturer's instructions. The concentration of proteins was determined by bicinchoninic acid (BCA) assay and denatured by boiling water bath. The proteins were separated using $10 \%$ sodium dodecyl sulphate-polyacrylamide gel electrophoresis (SDS-PAGE) and blotted onto the PVDF membranes. Then the membranes were blocked with $5 \%$ bovine serum albumin at $37^{\circ} \mathrm{C}$ for $2 \mathrm{~h}$ and incubated with anti-GST monoclonal antibody (1:1,000 dilution), anti-S100A8 monoclonal antibody (1:1,000 dilution), anti-CD284 (TLR4) polyclonal antibody (1:1,000 dilution), anti-phospho-NF- $\kappa \mathrm{B}$ p65 (Ser536) (93H1) antibody (1:1,000 dilution), anti-histone H3.1 monoclonal antibody (1:5,000 dilution), or anti- $\beta$-actin monoclonal antibody (1:1,000 dilution) and then with a relevant secondary antibody conjugated with horseradish peroxidase (1:5,000 dilution). The proteins of interest on the membranes were detected using an ECL kit. The results were recorded using the Bio-Rad Electrophoresis Documentation (Gel Doc 1000) and Quantity One version 4.5.0 software (Bio-Rad Laboratories, Inc., Hercules, CA, USA).

Preparation of macrophage conditioned medium. Differentiated THP-1 macrophages in $100 \mathrm{~mm}$ dishes were treated without and with LPS, GST and GST-hS100A8 for $24 \mathrm{~h}$ and the medium was collected, filtered and used as macrophage CM.

Cell viability assay. An MTT assay was used to evaluate the cell viability. The cells were seeded in 96-well plates and exposed to the different treatments. After the indicated incubation time, $10 \mu \mathrm{l}$ of MTT reagent was added into the wells respectively, followed by another $4 \mathrm{~h}$ of incubation at $37^{\circ} \mathrm{C}$. Dimethyl sulfoxide $(100 \mathrm{ml})$ was added to dissolve the formazan product for $10 \mathrm{~min}$ at room temperature. Finally, the absorbance was measured daily for the following five days at $492 \mathrm{~nm}$ using a microplate reader. Each treatment was performed in quintuplicate, and the overall experiment was repeated thrice.

Immunofluorescence staining. Differentiated THP-1 macrophages were seeded on sterile glass coverslips in 24-well culture plates and treated without and with LPS, GST and GST-hS100A8 in serum-free RPMI-1640 medium for the indicated time. The cells were washed with PBS, fixed with methanol at room temperature, and permeabilized with $0.25 \%$ Triton $\mathrm{X}-100$ at $37^{\circ} \mathrm{C}$ for $15 \mathrm{~min}$. After being blocked with goat serum for $30 \mathrm{~min}$ at $37^{\circ} \mathrm{C}$, the cells were incubated with anti-CD284 (TLR4) polyclonal antibody or anti-phospho-NF- $\mathrm{B}$ p65 (Ser536) (93H1) antibody (1:200 dilution in PBS) at $4^{\circ} \mathrm{C}$ overnight. Subsequently, the cells were rinsed with PBS to remove the primary antibody and incubated with Alexa Fluor 488-conjugated goat anti-rabbit IgG at a $1: 200$ dilution for $1 \mathrm{~h}$ at $37^{\circ} \mathrm{C}$ in the dark. Next, the cells were washed with PBS, counterstained with DAPI for $5 \mathrm{~min}$, washed again with PBS and then the coverslips were mounted using antifade mounting medium. The fluorescence of the different groups was viewed and photo- graphed with an inverted fluorescence microscope (Nikon Eclipse 80i; Nikon Corporation, Tokyo, Japan).

Transient transfection. Differentiated THP-1 macrophages were transfected with the miR-155 inhibitor or miR-NC at a final concentration of $100 \mathrm{nmol} / \mathrm{l}$ using Lipofectamine ${ }^{\mathrm{TM}} 2000$ according to the manufacturer's instructions. Then the cells were treated without and with LPS and GST-hS100A8 for $24 \mathrm{~h}$ and total RNA and the supernatant was collected to measure IL-1 $\beta$ and TNF- $\alpha$ by semi-quantitative RT-PCR (semi-PCR) and ELISA.

Total RNA isolation, semi-PCR and quantitative realtime PCR $(q P C R)$. Total RNA from the treated cells was extracted using TRIzol reagents, cDNA samples synthesized using random primers for IL-1 $\beta$, TNF- $\alpha$ and GAPDH with real-time (RT)-PCR kit according to the manufacturer's instructions were used as templates for semi-PCR. Semi-PCR products were identified by electrophoresis with $2 \%$ agarose gels and recorded using the Gel Doc 1000 imaging system. cDNA samples synthesized using specific primers for miRNAs and U6 (GenScript Co., Ltd., Nanjing, China) were used as templates for the detection of miRNAs by quantitative qPCR. qPCR was performed on the CFX96 real-time PCR detection system from Bio-Rad using SYBR Premix Ex Taq ${ }^{\mathrm{TM}}$ II. Data were collected and analyzed by the comparative $2^{-\Delta \Delta \mathrm{Ct}}$ method with U6 as the control. The primers in this study are shown in Table I.

Gaussia luciferase activity assay. Gaussia luciferase reporter assay was carried out as previously described (24). Differentiated THP-1 macrophages were evenly seeded in a 24-well plate and transfected with $\mathrm{pNF}-\kappa \mathrm{B}-\mathrm{luc}$ plasmid using Lipofectamine ${ }^{\mathrm{TM}} 2000$ according to the manufacturer's instructions. Then the cells were then treated without and with LPS, GST and GST-hS100A 8 for $24 \mathrm{~h}$ or pretreated with Bay 11-7082 for a period of $30 \mathrm{~min}$ prior to the treatment. Gaussia luciferase activity was measured using a Single Luciferase Reporter Assay system according to the manufacturer's instructions.

ELISA. Supernatant of differentiated THP-1 macrophages in different groups was collected, centrifuged at $1,000 \mathrm{x} \mathrm{g}$ for $20 \mathrm{~min}$ and stored at $-80^{\circ} \mathrm{C}$. Specific ELISA kits were used for measuring IL- $1 \beta$ and TNF- $\alpha$ according to the manufacturer's instructions.

Flow cytometric analysis. HCT116 cells were co-cultured with differentiated THP-1 macrophages which were treated without and with LPS, GST and GST-hS100A8 or pretreated with Bay 11-7082. After being treated for $24 \mathrm{~h}$, the cells were harvested by trypsinization and fixed with $70 \%$ ice-cold ethanol for at $4^{\circ} \mathrm{C}$ overnight. Cell cycle distribution was analyzed by using a FACSVantage SE flow cytometer (Becton-Dickinson, San Jose, CA, USA).

Hoechst staining assay. The Hoechst staining assay was performed according to the manufacturer's instructions using Hoechst 33258 . The HCT116 cells seeded in 24-well plates were co-cultured with the differentiated THP-1 macrophages which 
Table I. The primers used in this study.

\begin{tabular}{lll}
\hline Gene & & \multicolumn{1}{c}{ Sequences } \\
\hline GAPDH & Forward primer: & 5'-CAGCGACACCCACTCCTC-3' \\
& Reverse primer: & 5'-TGAGGTCCACCACCCTGT-3' \\
IL-1 $\beta$ & Forward primer: & 5'-GCCCTAAACAGATGAAGTGCTC-3' \\
& Reverse primer: & 5'-GCCCTAAACAGATGAAGTGCTC-3' \\
TNF- $\alpha$ & Forward primer: & 5'-CAGCCTCTTCTCCTTCCTGA-3' \\
& Reverse primer: & 5'-GGAAGACCCCTCCCAGATAGA-3' \\
hsa-miR-155-5p & RT primer: & 5'-CTCAACTGGTGTCGTGGGTCGGCAATTCAGTTGAGACCCCTAT-3' \\
& Forward primer: & 5'-ACACTCCAGCTGGGTTAATGCTAATCGTGAT-3' \\
& Reverse primer: & 5'-TGGTGTCGTGGAGTCG-3' \\
& RT primer: & 5'-AACGCTTCACGAATTTGCGT-3' \\
& Forward primer: & 5'-AACGCTTCACGAATTTGCGT-3' \\
& Reverse primer: & 5'-AACGCTTCACGAATTTGCGT-3' \\
& &
\end{tabular}

A

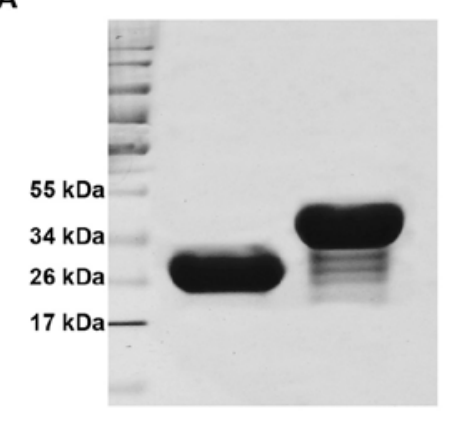

B

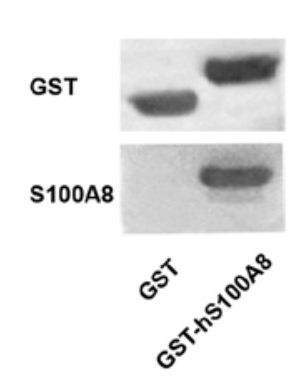

C

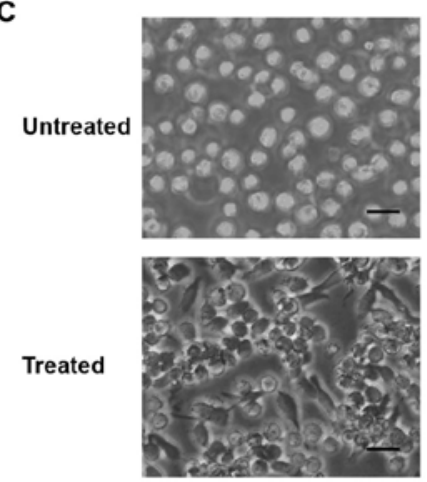

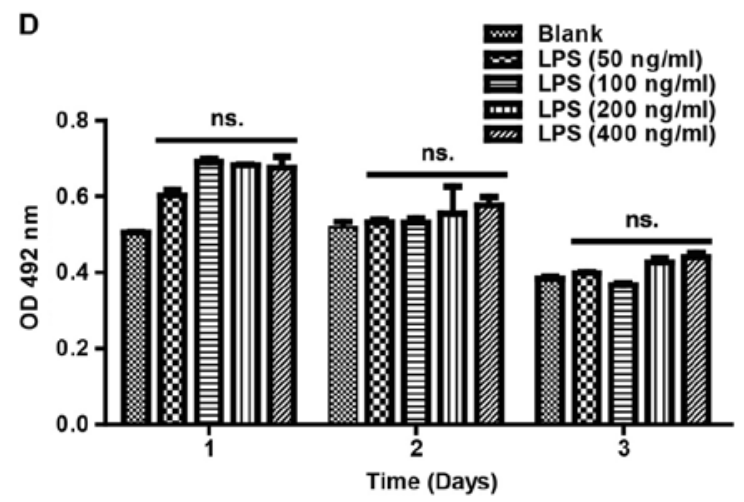

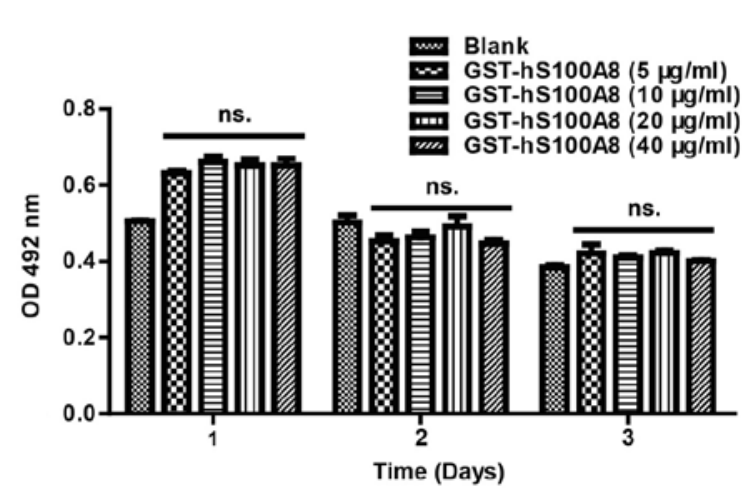

Figure 1. Characterization of the human THP-1 cell line. (A) Recombinant protein GST-hS100A8 was found to be $\sim 37 \mathrm{kDa}$, and GST was $\sim 26 \mathrm{kDa}$; their purities were $>90 \%$ (by Quantity One software). (B) GST-hS100A8 was recognized by anti-GST and anti-S100A8 antibodies by western blot analysis. Left lane, GST protein; right lane, GST-hS100A8 protein. (C) Morphological changes of THP-1 cells with differentiation. Representative differential contrast images of THP-1 cells treated with or without PMA. Black scale bars, $10 \mu \mathrm{m}$. (D) MTT assay. The viability of the differentiated THP-1 cells treated with different concentrations of LPS or GST-S100A8 was detected by MTT assay at 24, 48 and $72 \mathrm{~h}$, as described in Materials and methods. The absorbance was measured at $492 \mathrm{~nm}$ using a microplate reader. The results represent the mean absorbance \pm SEM of 5 independent experiments. ns., P $>0.05$, as compared with each group. PMA, Phorbol myristate acetate; LPS, lipopolysccharides.

were treated without and with LPS, GST and GST-hS100A8 or pretreated with Bay 11-7082 for $24 \mathrm{~h}$. Then the cells were fixed with $4 \%$ paraformaldehyde for 10 min and stained with Hoechst staining solution (1:1,000 dilution) for $30 \mathrm{~min}$ at room temperature in the dark. Finally, the cells were viewed under an inverted fluorescence microscope. Each experiment was performed three times.
Wound healing assay. HCT116 and SW480 cells were seeded into 6-well culture plates and incubated at $37^{\circ} \mathrm{C}$ until the cells grew to $95 \%$ confluency. A wound was made in the center of the cell monolayers with a $10-\mu 1$ sterile plastic pipette tip, and the well was washed with PBS three times and incubated in serum-free DMEM. Differentiated THP-1 macrophages seeded into the upper inserts (Millipore Corporation) and 


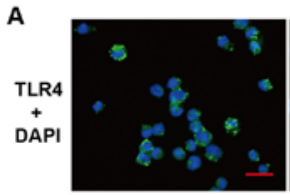

Blank

B

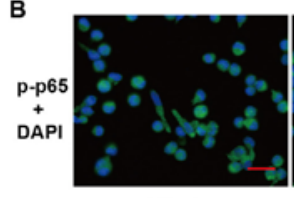

Blank

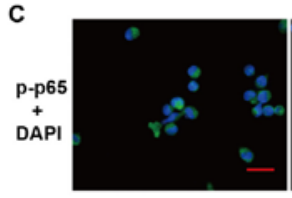

$\mathrm{Oh}$

D
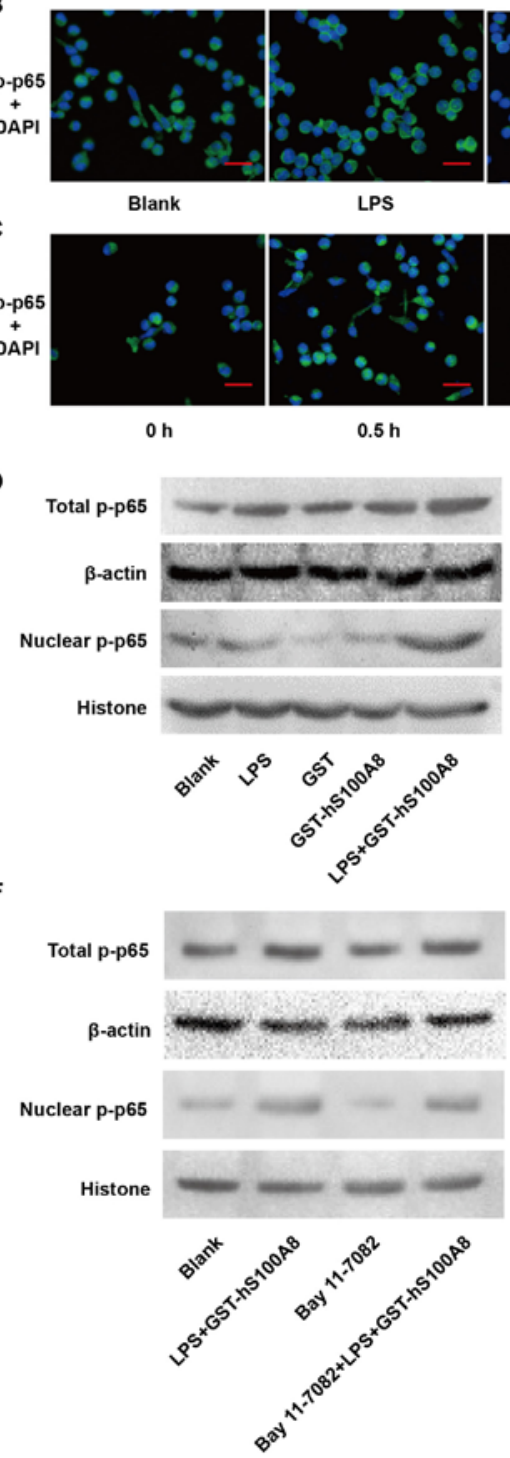
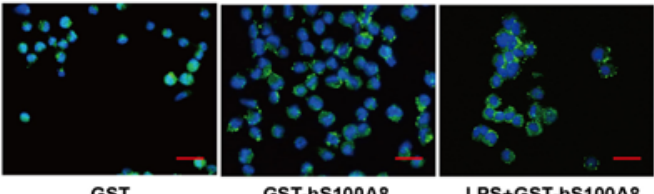

GST-hS100A8

LPS+GST-hS100A8

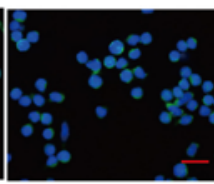

GST

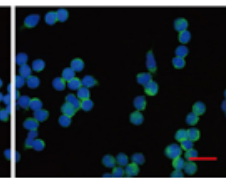

GST-hS100A8
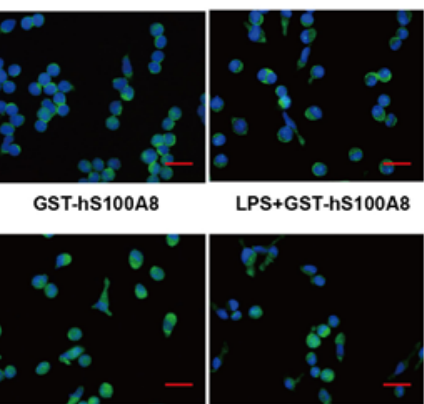

$2 \mathrm{~h}$

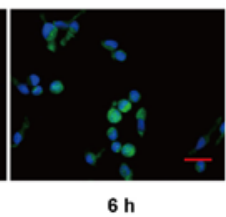

E

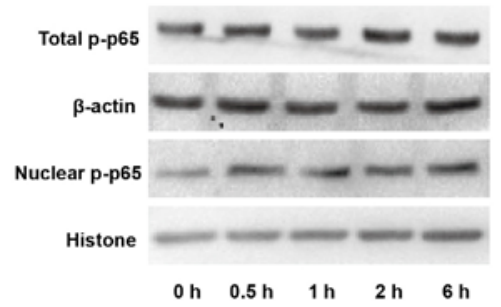

G

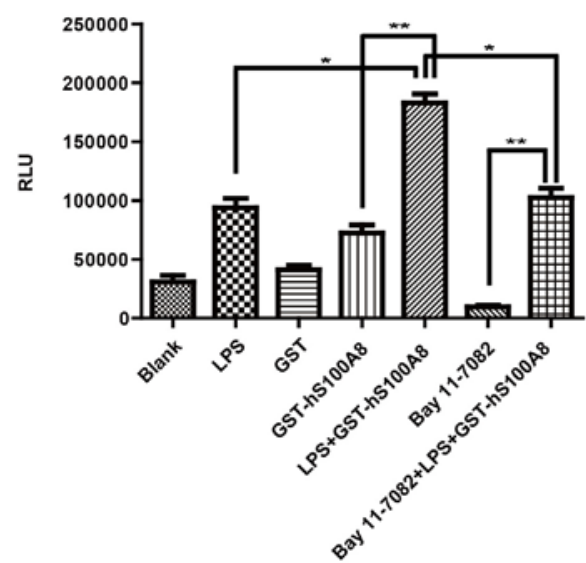

Figure 2. Recombinant S100A8 protein induces the activation of TLR4 and NF- $\mathrm{BB}$ in macrophages in an inflammatory microenvironment. (A) Macrophages were not treated or treated with LPS (100 ng/ml), GST $(10 \mu \mathrm{g} / \mathrm{ml})$, GST-hS100A8 (10 $\mu \mathrm{g} / \mathrm{ml})$ and LPS+ GST-hS100A8 for $24 \mathrm{~h}$, and the expression of TLR4 was determined by immunofluorescence staining. (B) Macrophages were not treated or treated with LPS (100 ng/ml), GST (10 $\mu \mathrm{g} / \mathrm{ml}), \mathrm{GST}-\mathrm{hS} 100 \mathrm{~A} 8$ (10 $\mu \mathrm{g} /$ $\mathrm{ml})$ and LPS+ GST-hS100A8 for $1 \mathrm{~h}$ or (C) treated with LPS (100 ng/ml) and GST-hS100A8 (10 $\mu \mathrm{g} / \mathrm{ml})$ for 0, 0.5, 1, 2, 6 and $12 \mathrm{~h}$, and nuclear translocation of p-NF- $\mathrm{B}$ p 65 was determined by immunofluorescence staining. The representative images are shown. Red scale bars, $10 \mu \mathrm{m}$. (D and E) Macrophages were treated as above and total and nuclear p-NF- $\mathrm{B}$ p 65 proteins were assessed by western blot analysis. (F) Macrophages were pretreated with an inhibitor of $\mathrm{NF}-\kappa \mathrm{B}$ (Bay 11-7082, $50 \mathrm{ng} / \mathrm{ml})$ for a period of $30 \mathrm{~min}$ prior to treatment for $24 \mathrm{~h}$ without or with LPS (100 ng/ml) and GST-hS100A8 (10 $\mu \mathrm{g} / \mathrm{ml})$. Total and nuclear p-NF- $\mathrm{B}$ p65 proteins were assessed by western blot analysis. $\beta$-actin and histone were used as internal reference controls. (G) Macrophages were transfected with the pNF- $\mathrm{BB}$-luc plasmid, then pretreated with Bay 11-7082 for a period of $30 \mathrm{~min}$ prior to treatment for $24 \mathrm{~h}$ without or with LPS (100 ng/ml), GST $(10 \mu \mathrm{g} / \mathrm{ml})$, GST-hS100A8 $(10 \mu \mathrm{g} / \mathrm{ml})$, LPS+ GST-hS100A8 and a combination of Bay 11-7082+LPS+GST-hS100A8. The luciferase activity of NF- $\kappa$ B was detected in the supernatant. ${ }^{*} \mathrm{P} \leq 0.05,{ }^{* *} \mathrm{P} \leq 0.01$ compared with the control group. TLR4, toll-like receptor 4 ; LPS, lipopolysaccharides.

treated without and with LPS, GST, GST-hS100A8 or pretreated with Bay 11-7082 were co-cultured with the above cells, respectively. Wound areas were observed and photographed at x100 magnification at $0,24,48$ and $72 \mathrm{~h}$.

Transwell migration assay. The Transwell migration assay was conducted using 24-well Transwell cell culture chambers
(Millipore Corporation). Briefly, HCT116 and SW480 cells were harvested after $24 \mathrm{~h}$ of co-culture with the differentiated THP-1 macrophages which were treated without and with LPS, GST and GST-hS100A8 or pretreated with Bay 11-7082. Then, $1 \times 10^{5}$ CRC cells were resuspended in $200 \mu \mathrm{l}$ of DMEM supplemented with $10 \% \mathrm{FBS}$, and added to the upper inserts. DMEM $(500 \mu 1)$ with $10 \%$ FBS was added to the lower 
A

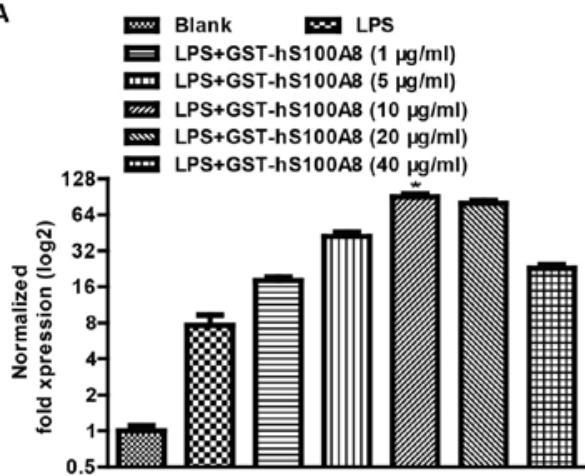

C

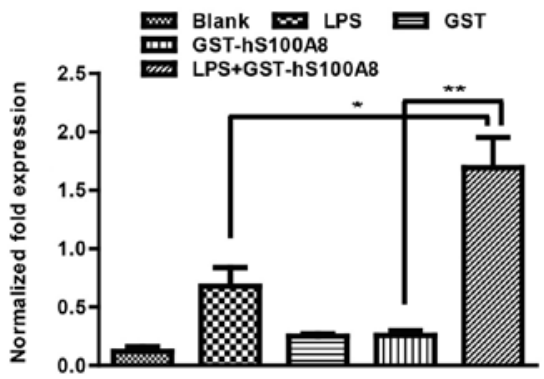

B

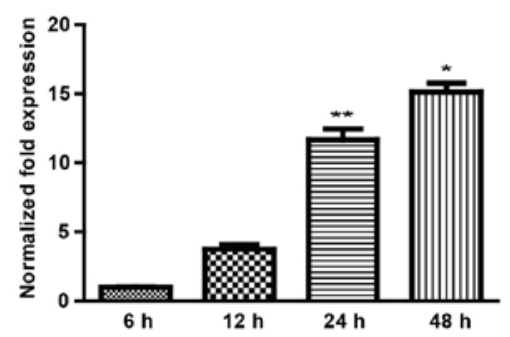

D

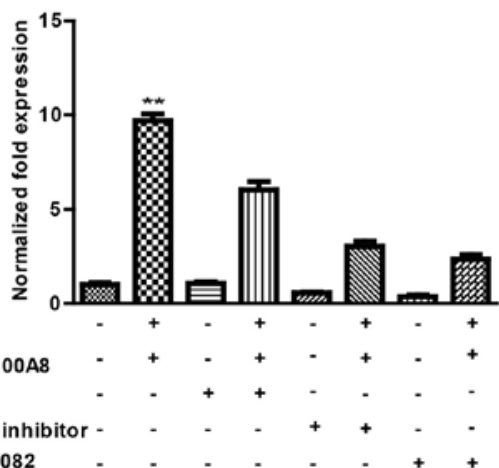

Figure 3. Recombinant S100A8 protein regulates expression of miR-155 in macrophages in an inflammatory microenvironment. The levels of miR-155 in the macrophages were detected by qPCR (U6 as an internal control). (A) Macrophages were treated with LPS (100 ng/ml) and different concentrations of GST-hS100A8 for $24 \mathrm{~h}$, or (B) treated with LPS (100 ng/ml) and GST-hS100A8 (10 $\mu \mathrm{g} / \mathrm{ml})$ for 6, 12, 24 and $48 \mathrm{~h}$. (C) Macrophages were treated with LPS $(100 \mathrm{ng} / \mathrm{ml})$, GST $(10 \mu \mathrm{g} / \mathrm{ml})$, GST-hS100A8 $(10 \mu \mathrm{g} / \mathrm{ml})$ and LPS+GST-hS100A8 for $24 \mathrm{~h}$. Data are represented as means \pm SEM of $3 \mathrm{independent} \mathrm{experi-}$ ments. ${ }^{*} \mathrm{P} \leq 0.05,{ }^{* *} \mathrm{P} \leq 0.01$, ANOVA. (D) Macrophages were transfected with the miR-155 inhibitor or miR-NC or pretreated with inhibitor of NF- $\kappa \mathrm{B}$ for a period of $30 \mathrm{~min}$ prior to treatment for $24 \mathrm{~h}$ without or with LPS (100 ng/ml), GST-hS100A8 (10 $\mu \mathrm{g} / \mathrm{ml})$. LPS, lipopolysaccharides.

chamber. After the CRC cells attached, the medium in the upper inserts was replaced with serum-free DMEM, and the medium in the lower chambers was replaced with $20 \%$ FBS DMEM. Twenty-four hours later, the migrated cells were fixed with methanol for $20 \mathrm{~min}$ and stained with $0.05 \%$ crystal violet for $30 \mathrm{~min}$. Cells on the upper surface of the insert membrane were removed with cotton swabs. The migrated cells were counted at x100 magnification in 10 different fields for each insert. The experiments were repeated three times.

Statistical analysis. All data are presented as mean \pm SEM (standard error of the mean). Differences were analyzed using the two-tailed Student's t-test for comparison between two groups or one-way ANOVA followed by Tukey's multiple comparison test. All the statistical analyses were performed using GraphPad Prism 5 (GraphPad Software, Inc., La Jolla, CA, USA). Significant probability values are indicated as $\mathrm{P}<0.05$

\section{Results}

Effects of LPS and recombinant S100A8 protein on the viability of the differentiated THP-1 macrophages. In this study, we first prepared GST and GST-hS100A8 proteins, which were identified by SDS-PAGE and western blot analysis (Fig. 1A and B). Their purities were confirmed to be $>90 \%$ by Quantity One software after SDS-PAGE and Coomassie Brilliant Blue staining (Fig. 1A). The purified proteins were used to treat cells in our subsequent experiments.
THP-1 is a human monocytic leukemia cell line, and it can be induced by PMA to differentiate into macrophage-like cells, which can mimic native monocyte-derived macrophages. After treatment with PMA, the cells were characterized by reduced proliferation, increased adherence and extended pseudopodia (Fig. 1C), indicating that the THP-1 cells were induced to differentiate into macrophages.

Secondly, the effects of LPS and S100A8 on the viability of the macrophages were assayed by the MTT assay. After the cells were treated with LPS at 0, 50, 100, 200 and $400 \mathrm{ng} / \mathrm{ml}$ or GST-hS100A 8 at $0,5,10,20$ and $40 \mu \mathrm{g} / \mathrm{ml}$ for 3 successive days, we found that there were no significant effects on cell viability compared to the control group (Fig. 1D).

S100A8activates the TLR4/NF- $\kappa$ B pathway in the macrophages in an inflammatory microenvironment. Previous studies have shown that TLR4 is the dominant receptor mediating S100A8 signaling in macrophages, and the NF- $\kappa \mathrm{B}$ pathway is consistently activated by the ligands of TLR4 $(25,26)$. We examined the effects of S100A8 on the activation of TLR 4 and NF- $\kappa$ B in the macrophages by immunofluorescence staining. The results showed that there was a more obvious activation on TLR4 following the treatment of the combination LPS and S100A8 as well as LPS or S100A8 respectively (Fig. 2A).

Next, we examined whether the treatment of LPS and S100A8 can transport $\mathrm{p}-\mathrm{NF}-\kappa \mathrm{B}$ p 65 to the nucleus. Our results confirmed that $\mathrm{S} 100 \mathrm{~A} 8$ promoted $\mathrm{p}-\mathrm{NF}-\kappa \mathrm{B}$ p 65 nuclear translocation and was more significant in the inflammatory microenvironment (Fig. 2B). Moreover, as shown in Fig. 2C, the treatment of LPS and S100A8 
A
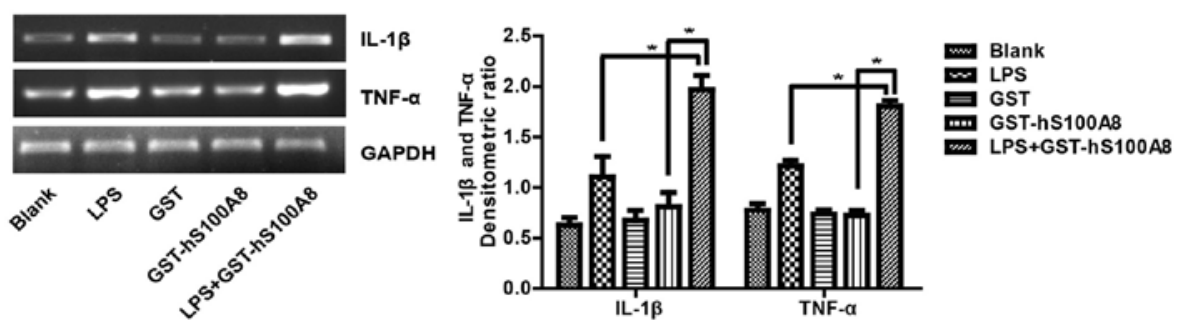

B
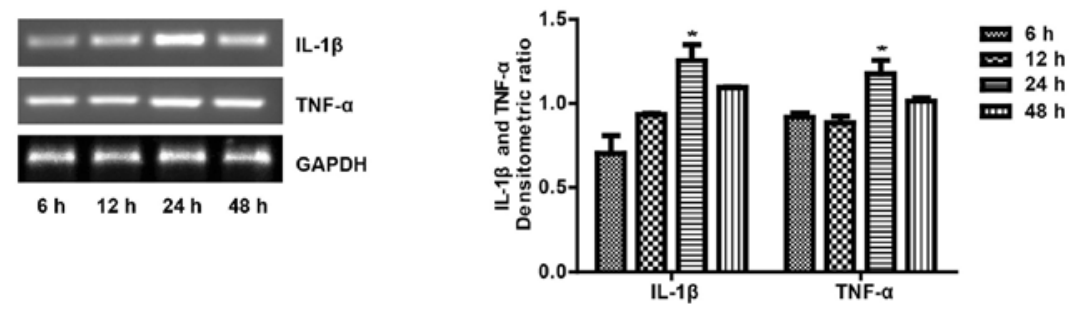

C
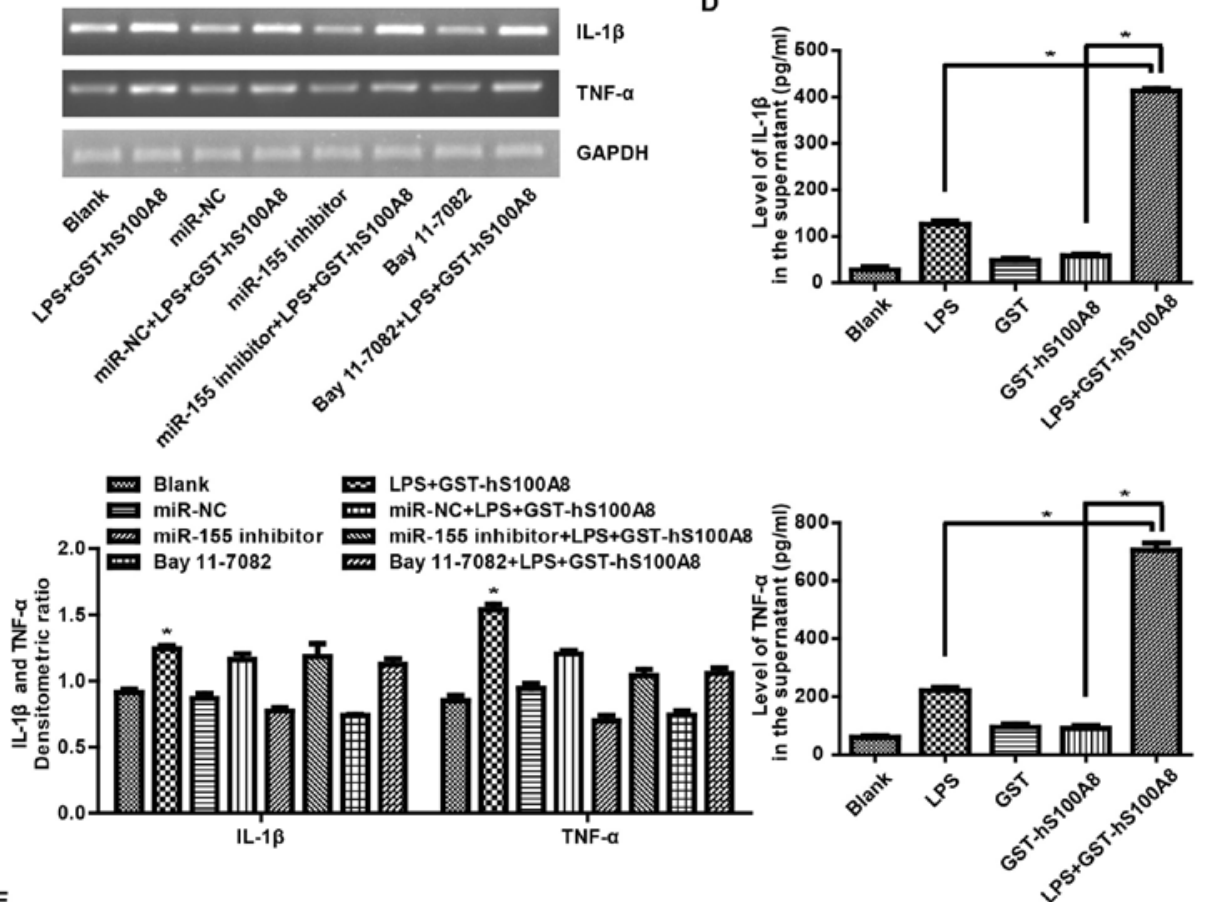

E

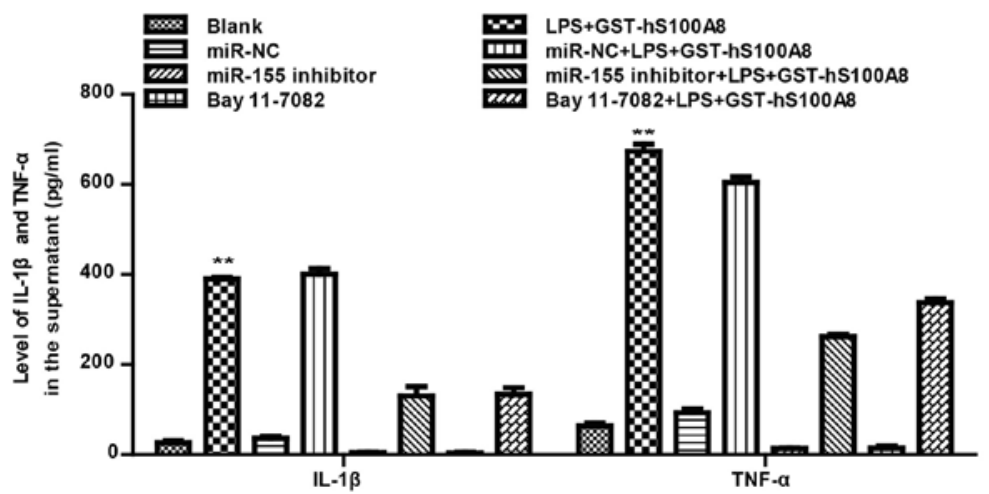

Figure 4. Recombinant S100A8 protein strengthens the secretion of IL-1 $\beta$ and TNF- $\alpha$ in macrophages in an inflammatory microenvironment. (A) Macrophages were not treated or treated with LPS $(100 \mathrm{ng} / \mathrm{ml})$, GST $(10 \mu \mathrm{g} / \mathrm{ml})$, GST-hS100A8 $(10 \mu \mathrm{g} / \mathrm{ml})$ or LPS+GST-hS100A8 for $24 \mathrm{~h}$ or $(\mathrm{B})$ not treated or treated with LPS $(100 \mathrm{ng} / \mathrm{ml})$, GST-hS100A8 $(10 \mu \mathrm{g} / \mathrm{ml})$ for $6,12,24$ or $48 \mathrm{~h}$ and the mRNA of IL- $1 \beta$ and TNF- $\alpha$ were determined by RT-PCR. GAPDH was used as an internal reference control. (C) Macrophages were transfected with miR-155 inhibitor or miR-NC or pretreated with the inhibitor of NF- $\mathrm{KB}$ for a period of $30 \mathrm{~min}$ prior to treatment for $24 \mathrm{~h}$ without or with LPS $(100 \mathrm{ng} / \mathrm{ml})$, GST-hS100A8 $(10 \mu \mathrm{g} / \mathrm{ml})$ or LPS+GST-hS100A8. Then, mRNA levels of IL-1 $\beta$ and TNF- $\alpha$ were determined by RT-PCR. GAPDH was used as an internal reference control. (D) Macrophages were not treated or treated with LPS (100 ng/ml), GST $(10 \mu \mathrm{g} / \mathrm{ml})$ or GST-hS100A8 $(10 \mu \mathrm{g} / \mathrm{ml})$ for $24 \mathrm{~h}$ and IL-1 $\beta$ and TNF- $\alpha$ in the supernatant were analyzed by ELISA. (E) Macrophages were transfected with miR-155 inhibitor or miR-NC or pretreated with the inhibitor of NF-kB for a period of $30 \mathrm{~min}$ prior to treatment for $24 \mathrm{~h}$ without or with LPS (100 ng/ml), GST-hS100A8 $(10 \mu \mathrm{g} / \mathrm{ml})$ or LPS+GST-hS100A8 and IL-1 $\beta$ and TNF- $\alpha$ in the supernatant were analyzed by ELISA. ${ }^{*} \leq 0.05,{ }^{* *} \mathrm{P} \leq 0.01$ compared to the control group. LPS, lipopolysaccharides. 

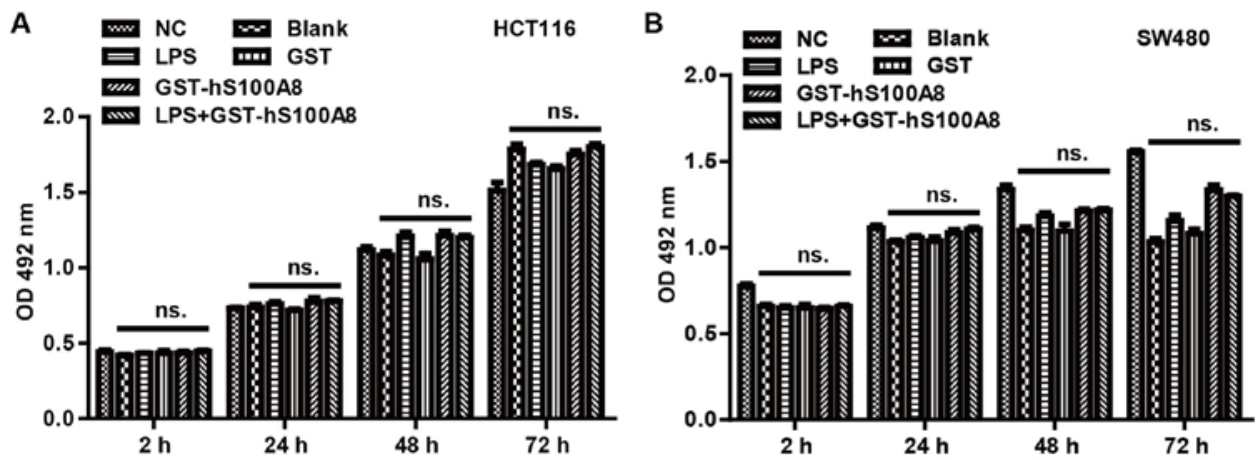

C
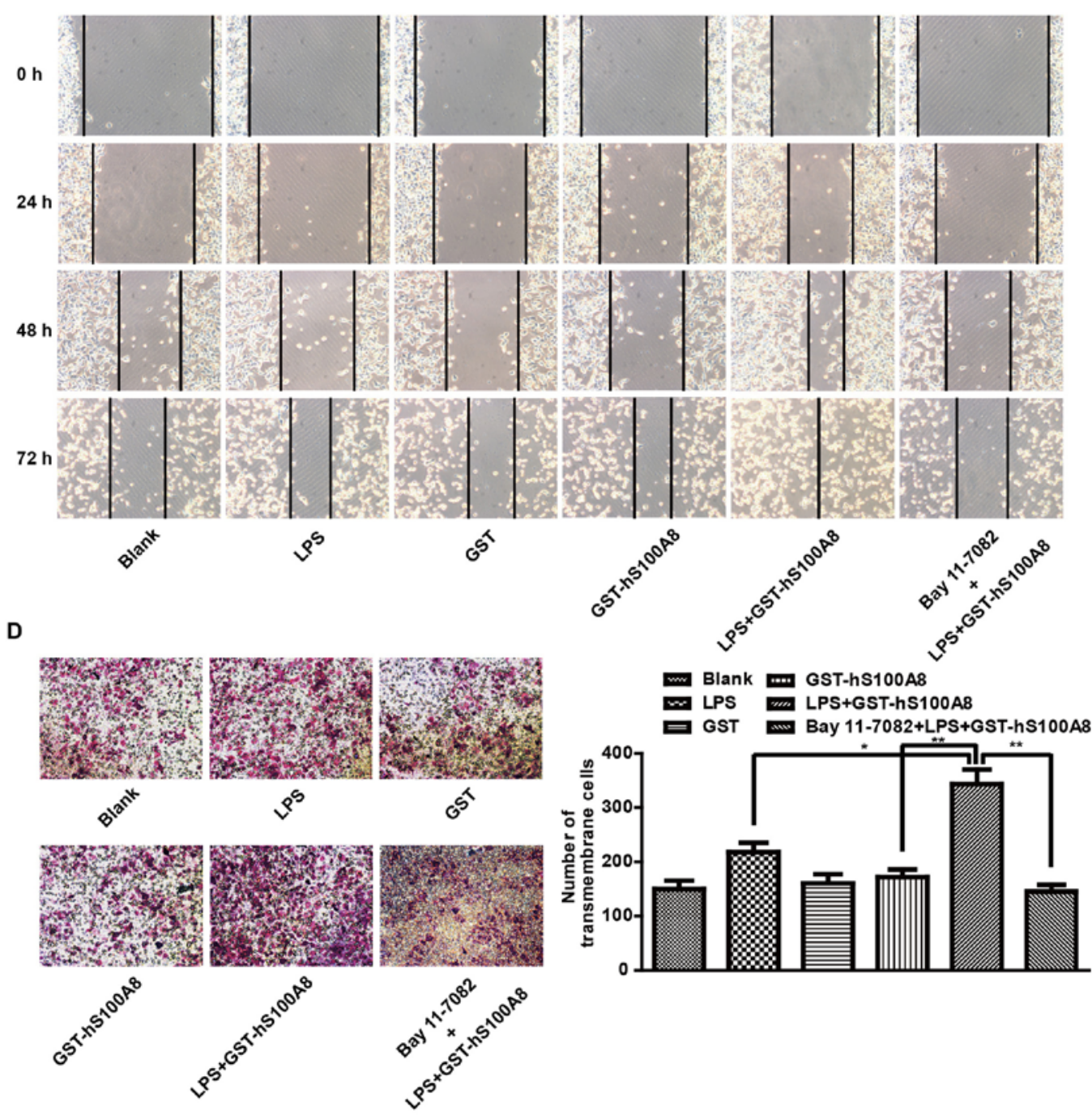

Figure 5. Recombinant S100A8 protein facilitates the migration of CRC cells co-cultured with macrophages through activation of NF- $\mathrm{kB}$ in an inflammatory microenvironment. (A) HCT116 and (B) SW480 cells were treated with the different macrophage conditioned media for 2, 24, 48 and 72 h, and the viability was measured using the MTT assay. Results are expressed as the mean absorbances \pm SEM of 5 independent experiments. (C) Wound healing assay for analyzing the effects of S100A8 on the migration of SW480 cells co-cultured with macrophages for $0,24,48$ and $72 \mathrm{~h}$ which were not treated or treated with LPS $(100 \mathrm{ng} / \mathrm{ml})$, GST and GST-hS100A8 $(10 \mu \mathrm{g} / \mathrm{ml})$ and LPS+GST-hS100A8. The incision width of different sites was measured. (D) Transwell migration assay for analyzing the migration of HCT116 cells co-cultured with macrophages for $24 \mathrm{~h}$ which were not treated or treated with LPS (100 ng/ml), GST or GST-hS100A8 $(10 \mu \mathrm{g} / \mathrm{ml})$ and LPS+GST-hS100A8. Representative images of transmembrane cells are shown. The mean of transmembrane cells \pm SEM per microscopic field of 3 independent experiments was calculated. Magnification, x100. ns., $\mathrm{P}>0.05 ;{ }^{*} \mathrm{P} \leq 0.05,{ }^{* *} \mathrm{P} \leq 0.01$ compared with the control group. CRC colorectal cancer; LPS, lipopolysaccharides.

significantly promoted $\mathrm{p}-\mathrm{NF}-\mathrm{kB}$ p65 nuclear translocation and reached a peak value $1 \mathrm{~h}$ after treatment

To further confirm that S100A8 facilitates p-NF-кB p65 nuclear translocation in the inflammatory microenvironment, western blot analysis was performed to detect the distribution of p-NF- $\kappa \mathrm{B}$ p65 in macrophages. We found that the levels of total and nuclear p-NF-кB p65 were elevated much more after the treatment of LPS and S100A8 together than these 
levels in the control group (Fig. 2D). Moreover, the levels of nuclear $\mathrm{p}-\mathrm{NF}-\kappa \mathrm{B}$ p 65 were increased after the treatment of LPS and S100A8 with time, but the levels of total p-NF- $\kappa$ B p65 were not significantly altered (Fig. 2E). The treatment of LPS and S100A8 together partially reversed the suppressive effect of Bay 11-7082 on the macrophages (Fig. 2F). Furthermore, a luciferase activity assay was used to analyze the activation of the NF- $\kappa \mathrm{B}$ pathway. S100A8 significantly increased luciferase activity of $\mathrm{NF}-\kappa \mathrm{B}$ in the inflammatory microenvironment and partially reversed the suppressive effect of Bay 11-7082 (Fig. 2G). These findings indicated that the recombinant $\mathrm{S} 100 \mathrm{~A} 8$ protein could distinctly activate the TLR4/NF- $\kappa \mathrm{B}$ signaling pathway of macrophages in an inflammatory microenvironment.

S100A8 promotes miR-155 expression through activation of the $N F-\kappa B$ pathway. It is well known that miR-155 is an oncogenic RNA that has been shown to be critical in the crosstalk between inflammation and cancer (27). To test whether S100A8 can regulate the expression of miR-155 in an inflammatory microenvironment, we first investigated the influence of S100A8 on the expression of miR-155 at different protein concentrations and treatment times. After the macrophages were treated without and with LPS (100 ng/ $\mathrm{ml})$ and GST-hS100A8 at $0,5,10,20$, and $40 \mu \mathrm{g} / \mathrm{ml}$ for $24 \mathrm{~h}$, we found that LPS $(100 \mathrm{ng} / \mathrm{ml})$ and GST-hS100A8 at $10 \mu \mathrm{g} / \mathrm{ml}$ had a more significant effect on expression of miR-155 (Fig. 3A). After the macrophages were treated with a combination of LPS (100 ng/ml) and GST-hS100A8 $(10 \mu \mathrm{g} /$ $\mathrm{ml}$ ) for $6,12,24$ and $48 \mathrm{~h}$, we found that the expression of miR-155 was increased with time (Fig. 3B). It should be noted that S100A8 upregulated the expression of miR-155 in a time-dependent manner. In addition, after the macrophages were treated without and with LPS (100 ng/ml), GST, GST-hS100A8 at $10 \mu \mathrm{g} / \mathrm{ml}$ for $24 \mathrm{~h}$, we found an obvious increase in the expression of miR-155 following the treatment of a combination of LPS and S100A8 compared with that of the other groups (Fig. 3C) and treatment of LPS and S100A8 partially reversed the suppressive effect of the miR-155 inhibitor (Fig. 3D). However, following pretreatment with Bay 11-7082 for a period of $30 \mathrm{~min}$ prior to the treatment of LPS and S100A8 for $24 \mathrm{~h}$, the expression of miR-155 was decreased compared with that of the treatment of the combination of LPS and S100A8 (Fig. 3D).

Collectively, these results suggested that S100A8 induced the upregulation of miR-155 expression and depended on the activation of the $\mathrm{NF}-\kappa \mathrm{B}$ pathway.

S100A8-induced upregulation of miR-155 enhances the secretion of inflammatory cytokines in the macrophages in the inflammatory microenvironment. It has been previously reported that inflammatory cytokines are mainly derived from immune cells such as monocyte/macrophages and dendritic cells (28) and miR-155 regulates inflammatory cytokine production in tumor-associated macrophages (29). To determine whether miR-155 expression is involved in the secretion of inflammatory cytokines in macrophages, we detected the mRNA of IL-1 $\beta$ and TNF- $\alpha$ and their protein levels in supernatant by RT-PCR and ELISA respectively. The results showed that treatment with the combination of
LPS and S100A8 had a more significant effect compared to other groups (Fig. 4A), and that the treatment with LPS and S100A8 increased the mRNA levels with time and reaching a peak value at $24 \mathrm{~h}$ (Fig. 4B). Similarly, after treatment of LPS and S100A8 for $24 \mathrm{~h}$, we found a significant increase in the levels of IL- $1 \beta$ and TNF- $\alpha$ in the supernatant compared to the other groups (Fig. 4C). Further analysis showed that the levels of IL-1 $\beta$ and TNF- $\alpha$ mRNA in the macrophages were reduced after transfection with the miR-155 inhibitor or pretreatment with Bay 11-7082 (Fig. 4D) and the secretion of IL-1 $\beta$ and TNF- $\alpha$ in the supernatant was markedly decreased after transfection with the miR-155 inhibitor or pretreatment with Bay 11-7082 (Fig. 4E). Analyzing the above results, it was determined that recombinant S100A8 protein enhanced the secretion of inflammatory cytokines in macrophages in the inflammatory microenvironment and this effect was through activation of $\mathrm{NF}-\kappa \mathrm{B}$ signaling and aberrant expression of miR-155.

S100A8 facilitates the migration but not the viability of CRC cells co-cultured with macrophages through the activation of $N F-\kappa B$ in the inflammatory microenvironment. Compelling evidence from human and experimental tumors indicated that tumor-associated macrophages (TAM) release a broad array of cytokines, growth factors and enzymes to promote the proliferation and metastasis of cancer cells $(30,31)$, particularly in spontaneous intestinal tumorigenesis, which has proven the importance of inflammatory cytokines in facilitating tumor promotion and progression (5). To investigate the effects of S100A8 on the viability and migration of CRC cells co-cultured with macrophages in an inflammatory microenvironment, an MTT assay was first conducted to measure the proliferation of HCT116 and SW480 cells after treatment with different macrophage CM (Fig. 5A and B). FCM was used to analyze the cell cycle and Hoechst 33258 fluorescent staining was performed to detect the cell apoptosis of HCT116 cells co-cultured with macrophages after the different treatments (data not shown). The above experimental methods were described in Materials and methods. It was established that there was no significant difference in viability among the six groups. Furthermore, a wound healing assay was used to detect the migration of SW480 cells co-cultured with macrophages after different treatments. There was a significant increase in the wound closure rate after being co-cultured with macrophages which were treated with LPS and S100A8 together compared with that of the other groups, and the effects were impaired by Bay 11-7082 (Fig. 5C). Similar results were observed in HCT116 cells (data not shown). The effect on cell migration by LPS and S100A8 co-treatment was further confirmed by Transwell migration assay, which showed that the number of trans-membrane migrated HCT116 cells after treatment with LPS and S100A8 was markedly increased compared with that of the other groups, but its effects were impaired by Bay 11-7082 (Fig. 5D). Similar results were observed in SW480 cells (data not shown). It is suggested that inflammatory cytokines produced in excess after the treatment of LPS and S100A8 in macrophages facilitated the migration of CRC cells, but there was no significant difference in terms of viability of CRC cells. 


\section{Discussion}

Increasing evidence indicates that the expression of S100A8 is increased in CRC tissues and the elevated expression of S100A8 is associated not only with histological differentiation, but also with Dukes' stage and lymph node metastasis in CRC (9). In the present study, we found that S100A8 promoted the expression of miR-155 and the secretion of IL- $1 \beta$ and TNF- $\alpha$ through activation of the NF- $\kappa \mathrm{B}$ signaling pathway in macrophages, eventually facilitating the migration of CRC cells, which occurred in the inflammation environment mimicked by LPS. These findings suggest that S100A8 may be an important proinflammatory factor involved in CRC progression. Aberrant expression of miR-155 and secretion of inflammatory cytokines may be involved in the oncogenic properties of S100A8.

The pivotal role of the tumor inflammatory microenvironment in tumor progression has been generally accepted, and $\mathrm{CRC}$ represents a paradigm, as in CRC there is clear evidence that persistent inflammation is linked to increasing cancer risk and tumor development (32). The tumor inflammatory microenvironment has been shown to be composed of tumor cells, infiltrating immune cells and various inflammatory cytokines. The immune cells and macrophages play a crucial role (4) in the tumor inflammatory microenvironment. Macrophages possess a high degree of functional plasticity, and they can alter their functional profiles time and again in response to environmental changes anywhere between the two extremes of their phenotypical programs, M1 and M2 polarization (33). It has been shown that macrophages are polarized to M1 macrophages when exposed to LPS and IFN- $\gamma$ and exhibit an antitumor effect, when exposed to Th2 cytokines (such as IL-4 and IL-13), they are polarized to M2 macrophages and cause protumoral progression $(34,35)$. Although previous studies indicated that TAMs, which are derived from circulating monocytes recruited at the tumor site by chemotactic factors, had several M2-associated protumoral functions including promotion of tumor cell growth, metastasis and suppression of adaptive immunity $(35,36)$, their role regarding tumor progression is still controversial. THP-1 macrophages were used as a macrophage model because PMA-treated THP-1 macrophages have an M2 functional profile (35,37). Hence, in this study, we used PMA to induce THP-1 monocytes to differentiate into macrophages with M2 functional profiles and investigated the effect of S100A8 in the modulation of macrophages and CRC cells in the inflammatory microenvironment.

Several studies have reported that CRC cells may be exposed to increased levels of LPS because of bacterial translocation (38) or systemic endogenous LPS without infections (39). It is suggested that LPS is an important component in the inflammatory microenvironment. Although LPS causes significant systemic inflammation and increases hepatic recruitment and liver metastasis by CRC cells through TLR4 signaling (10), the impact of S100A8 in the modulation of macrophages in an LPS mimicking inflammatory microenvironment is very limited. Previous studies have shown that proliferation of differentiated THP-1 macrophages is stopped and adherence is not very firm, thus after the cells were treated with LPS and S100A8 for 3 successive days, the viability of the macrophages was decreased. The results suggested that different concentrations of LPS and S100A8 may have no significant effect on the viability of differentiated THP-1 macrophages.

It is well known that the NF- $\mathrm{B}$ signaling pathway plays a crucial role in immune-regulation and inflammatory response via the induction of inflammatory cytokines (such as IL-6, IL-1 $\beta$ and TNF- $\alpha$ ), cyclooxygenase-2 (COX-2) and inducible nitric oxide synthase (iNOS) (40). For instance, transcriptional activity of NF- $\kappa \mathrm{B}$ may be most critical in S100A8/A9-induced expression of proinflammatory cytokines in monocytes/macrophages (41). S100A9 promoted human embryo lung fibroblasts to secrete proinflammatory cytokines through activation of the NF- $\mathrm{BB}$ pathways (42). Additionally, S100A4 induced an inflammatory response partially mediated by activation of $\mathrm{NF}-\kappa \mathrm{B}$ in mononuclear cells from patients with RA (43). On the contrary, bergamot juice can inhibit LPS-induced proinflammatory cytokines involved in the inhibition of $\mathrm{NF}-\kappa \mathrm{B}$ activation (40). In accordance with these studies, our data showed that S100A8 significantly activated the NF- $\mathrm{BB}$ pathway in macrophages in the inflammatory microenvironment and promoted both gene expression and secretion of inflammatory cytokines (IL-1 $\beta$ and TNF- $\alpha$ ). Moreover, an inhibitor of $N F-\kappa B$ partially reversed the activation of $N F-\kappa B$ and expression of inflammatory cytokines induced by S100A8 in the inflammatory microenvironment. Several studies have reported that S100A8 activated $\mathrm{NF}-\kappa \mathrm{B}$ in a TLR4-dependent manner $(25,44)$. Although we found that LPS and/or S100A8 treatment could elevate the activation of TLR4, to substantiate this idea, neutralization of TLR4 should be used to block TLR4 signaling and elucidate the mechanisms of S100A8 in CRC progression through the TLR4/NF- $\kappa \mathrm{B}$ signaling pathway. This will be investigated in our subsequent studies.

miR-155 is considered as an important oncomir and was first found within the third exon of B-cell integration cluster (BIC) gene (45) and is highly expressed in a variety of solid tumors, such as breast, lung and colon cancer (46-48). Recent research demonstrated that miR-155 was found to be induced by diverse TLR ligands through the NF- $\kappa \mathrm{B}$ signaling pathways (49). In our study, we found that S100A8 upregulated the expression of miR-155 in a time-dependent manner in the inflammatory microenvironment. This effect was dependent on the activation of the NF- $\kappa \mathrm{B}$ pathway. This confirmed the theory that the promoter region of pri-miR-155 contains putative NF- $\mathrm{BB}$ binding sites and NF- $\mathrm{B}$ may potentially modulate the miR-155 expression under certain circumstances (19-22). In addition, we found that aberrant miR-155 expression controlled gene expression of IL-1 $\beta$ and TNF- $\alpha$ and secretions of IL- $1 \beta$ and TNF- $\alpha$ in macrophages. It is possible that miR-155 post-transcriptionally modulates the expression of multiple target genes, including suppressor of cytokine signaling 1 (SOCS1) (16), forkhead box O3 (FOXO3a) (50), transcription factor CCAAT/enhancer binding protein $\beta(\mathrm{C} / \mathrm{EBP} \beta)(51)$, which were proven to regulate the expression of various inflammatory cytokines. Moreover, some studies have reported that TNF- $\alpha$ can significantly increase miR-155 expression in macrophages (52). It is consistent with the idea that increasing miR-155 production which is subjected to some proinflammatory mediators may be attributed to an autocrine loop (53).

Previous studies have reported that TAMs could directly activate tumor-promoting genes [such as COX-2, epidermal 
growth factor receptor (EGFR) and matrix metalloproteinase (MMP)] in cancer cells (54). Extensive evidence has confirmed that the inflammatory cytokines, secreted by macrophages, have a complicated role in the pathogenesis of IBD and CRC (5). Interestingly, inflammatory factors were not in equivalent levels in the intratumoral and peritumoral sites. IL-1 $\beta$, GM-CSF, G-CSF, TNF- $\alpha$, and IL- 6 were significantly increased in tumor tissues compared with adjacent non-tumor tissues $(55,56)$. IL-6 and IL-8 released from myofibroblasts were found to upregulate S100A8/A9 in tumor-infiltrated myeloid cells (57). However, our aforementioned data revealed that S100A8 enhanced the secretion of IL-1 $\beta$ and TNF- $\alpha$ in macrophages in the inflammatory microenvironment. In subsequent studies, we tested the the effects of S100A8 on the viability and migration of HCT116 and SW480 cells with macrophage CM or co-cultured with macrophages in the inflammatory microenvironment. Macrophage CM had no significant difference on proliferation in both cell lines as well as cell cycle and apoptosis, whereas migration was significantly increased in cells co-cultured with the macrophages stimulated by LPS and S100A8. These results are consistent with the notion that tumor-induced systemic inflammation contributes to metastases without influencing primary tumor progression (58). In the future, it is necessary to ascertain the effect of S100A8 on the development of CRC in xenograft tumor growth and lung metastasis in animal models.

Collectively, our data showed that S100A8 upregulated the expression of miR-155 through the activation of $\mathrm{NF}-\kappa \mathrm{B}$ by differentiating THP-1 macrophages in the inflammatory microenvironment, leading to the accumulation of the inflammatory cytokines IL- $1 \beta$ and TNF- $\alpha$, and ultimately facilitating the migration of colorectal cancer cells.

\section{Acknowledgements}

This study was supported by Chongqing Graduate Student Research Innovation Project Funding (no. CYS15133). We would like to thank T.C He (Medical Center, The University of Chicago) for the kind provision of the recombinant pGSTmoluc, pGST-moluc-hS100A8 and pNF-кB-luc plasmid.

\section{References}

1. Wang D, Fu L, Sun H, Guo L and Dubois RN: Prostaglandin E2 promotes colorectal cancer stem cell expansion and metastasis in mice. Gastroenterology 149: 1884-1895. e4, 2015.

2. Van den Eynden GG, Majeed AW, Illemann M, Vermeulen PB, Bird NC, Høyer-Hansen G, Eefsen RL, Reynolds AR and Brodt P: The multifaceted role of the microenvironment in liver metastasis: biology and clinical implications. Cancer Res 73: 2031-2043, 2013

3. Wang W, Li X, Zheng D, Zhang D, Huang S, Zhang X, Ai F, Wang X, Ma J, Xiong W, et al: Dynamic changes of peritoneal macrophages and subpopulations during ulcerative colitis to metastasis of colorectal carcinoma in a mouse model. Inflamm Res 62: 669-680, 2013.

4. Morales C, Rachidi S, Hong F, Sun S, Ouyang X, Wallace C, Zhang Y, Garret-Mayer E, Wu J, Liu B, et al: Immune chaperone gp96 drives the contributions of macrophages to inflammatory colon tumorigenesis. Cancer Res 4: 446-459, 2014.

5. De Simone V, Franzè E, Ronchetti G, Colantoni A, Fantini MC Di Fusco D, Sica GS, Sileri P, MacDonald TT, Pallone F, et al Th17-type cytokines, IL-6 and TNF- $\alpha$ synergistically activate STAT3 and NF- $\kappa \mathrm{B}$ to promote colorectal cancer cell growth Oncogene 34: 3493-3503, 2015.
6. Jia XH, Feng GW, Wang ZL, Du Y, Shen C, Hui H, Peng D, Li ZJ, Kong DL and Tian J: Activation of mesenchymal stem cells by macrophages promotes tumor progression through immune suppressive effects. Oncotarget: Mar 14, 2016. (Epub ahead of print).

7. Vrakas CN, O'Sullivan RM, Evans SE, Ingram DA, Jones CB, Phuong T and Kurt RA: The Measure of DAMPs and a role for S100A8 in recruiting suppressor cells in breast cancer lung metastasis. Immunol Invest 44: 174-188, 2015.

8. Chen B, Miller AL, Rebelatto M, Brewah Y, Rowe DC, Clarke L, Czapiga M, Rosenthal K, Imamichi T, Chen Y, et al: S100A9 induced inflammatory responses are mediated by distinct damage associated molecular patterns (DAMP) receptors in vitro and in vivo. PLoS One 10: e0115828, 2015.

9. Duan L, Wu R, Ye L, Wang H, Yang X, Zhang Y, Chen X, Zuo G, Zhang Y, Weng Y, et al: S100A8 and S100A9 are associated with colorectal carcinoma progression and contribute to colorectal carcinoma cell survival and migration via $\mathrm{Wnt} / \beta$-catenin pathway. PLoS One 8: e62092, 2013.

10. Stulík J, Osterreicher J, Koupilová K, Knízek, Macela A, Bures J, Jandík P, Langr F, Dedic K and Jungblut PR: The analysis of S100A9 and S100A8 expression in matched sets of macroscopically normal colon mucosa and colorectal carcinoma: the S100A9 and S100A8 positive cells underlie and invade tumor mass. Electrophoresis 20: 1047-1054, 1999.

11. Yang P, Li Z, Li H, Lu Y, Wu H and Li Z: Pyruvate kinase M2 accelerates pro-inflammatory cytokine secretion and cell proliferation induced by lipopolysaccharide in colorectal cancer. Cell Signal 27: 1525-1532, 2015.

12. Croce CM: Causes and consequences of microRNA dysregulation in cancer. Nat Rev Genet 10: 704-714, 2009.

13. Lujambio A and Lowe SW: The microcosmos of cancer Nature 482: 347-355, 2012.

14. Esquela-Kerscher A and Slack FJ: Oncomirs - microRNAs with a role in cancer. Nat Rev Cancer 6: 259-269, 2006.

15. Elton TS, Selemon H, Elton SM and Parinandi NL: Regulation of the MIR155 host gene in physiological and pathological processes. Gene 532: 1-12, 2013.

16. Pathak S, Grillo AR, Scarpa M, Brun P, D'Incà R, Nai L, Banerjee A, Cavallo D, Barzon L, Palù G, et al: MiR-155 modulates the inflammatory phenotype of intestinal myofibroblasts by targeting SOCS1 in ulcerative colitis. Exp Mol Med 47: e164, 2015 .

17. Mashima R: Physiological roles of miR-155. Immunology 145: 323-333, 2015.

18. Jin HM, Kim TJ, Choi JH, Kim MJ, Cho YN, Nam KI, Kee SJ, Moon JB, Choi SY, Park DJ, et al: MicroRNA-155 as a proinflammatory regulator via SHIP-1 down-regulation in acute gouty arthritis. Arthritis Res Ther 16: R88, 2014.

19. Thompson RC, Vardinogiannis I and Gilmore TD: Identification of an NF- $\mathrm{kB}$ p50/p65-responsive site in the human MIR155HG promoter. BMC Mol Biol 14: 24, 2013.

20. Quinn SR, Mangan NE, Caffrey BE, Gantier MP, Williams BR, Hertzog PJ, McCoy CE and O'Neill LA: The role of Ets2 transcription factor in the induction of microRNA-155 (miR-155) by lipopolysaccharide and its targeting by interleukin-10. J Biol Chem 289: 4316-4325, 2014.

21. Wang B, Majumder S, Nuovo G, Kutay H, Volinia S, Patel T, Schmittgen TD, Croce C, Ghoshal K and Jacob ST: Role of microRNA-155 at early stages of hepatocarcinogenesis induced by choline-deficient and amino acid-defined diet in C57BL/6 mice. Hepatology 50: 1152-1161, 2009.

22. Curtis AM, Fagundes CT, Yang G, Palsson-McDermott EM, Wochal P, McGettrick AF, Foley NH, Early JO, Chen L, Zhang H, et al: Circadian control of innate immunity in macrophages by miR-155 targeting Bmal1. Proc Natl Acad Sci USA 112: 7231-7236, 2015

23. You L, Xu LL, Guo YY, Zou ZY, Li YY, Sun SS, Luo JY and Zhou L: Prokaryotic expression, purification and identification of GST-human S100A9 fusion protein. Chin J Biochem Pharm 32: 253-256, 2011.

24. Zhao C, Wu N, Deng F, Zhang H, Wang N, Zhang W, Chen X, Wen S, Zhang J, Yin L, et al: Adenovirus-mediated gene transfer in mesenchymal stem cells can be significantly enhanced by the cationic polymer polybrene. PLoS One 9: e92908, 2014.

25. Deguchi A, Tomita T, Ohto U, Takemura K, Kitao A, Akashi-Takamura S, Miyake K and Maru Y: Eritoran inhibits S100A8-mediated TLR4/MD-2 activation and tumor growth by changing the immune microenvironment. Oncogene 35 , $1445-1456,2016$ 
26. Hiratsuka S, Watanabe A, Sakurai Y, Akashi-Takamura S, Ishibashi S, Miyake K, Shibuya M, Akira S, Aburatani H and Maru Y: The S100A8-serum amyloid A3-TLR4 paracrine cascade establishes a pre-metastatic phase. Nat Cell Biol 10: 1349-1355, 2008.

27. Tili E, Croce CM and Michaille JJ: miR-155: On the crosstalk between inflammation and cancer. Int Rev Immunol 28: 264-284, 2009.

28. Moldoveanu AC, Diculescu M and Braticevici CF: Cytokines in inflammatory bowel disease. Rom J Intern Med 53: 118-127, 2015.

29. Kurowska-Stolarska M, Alivernini S, Ballantine LE, Asquith DL, Millar NL, Gilchrist DS, Reilly J, Ierna M, Fraser AR, Stolarski B, et al: MicroRNA-155 as a proinflammatory regulator in clinical and experimental arthritis. Proc Natl Acad Sci USA 108: 11193-11198, 2011.

30. Pollard JW: Tumour-educated macrophages promote tumour progression and metastasis. Nat Rev Cancer 4: 71-78, 2004.

31. Mantovani A, Romero P, Palucka AK and Marincola FM: Tumour immunity: effector response to tumour and role of the microenvironment. Lancet 371: 771-783, 2008.

32. Erreni M, Mantovani A and Allavena P: Tumor-associated Macrophages (TAM) and Inflammation in Colorectal Cancer. Cancer Microenviron 4: 141-154, 2011.

33. Watkins SK, Egilmez NK, Suttles J and Stout RD: IL-12 rapidly alters the functional profile of tumor-associated and tumor-infiltrating macrophages in vitro and in vivo. J Immunol 178: 1357-1362, 2007

34. Edin S, Wikberg ML, Dahlin AM, Rutegård J, Öberg Å, Oldenborg PA and Palmqvist R: The distribution of macrophages with a M1 or M2 phenotype in relation to prognosis and the molecular characteristics of colorectal cancer. PLoS One 7: e47045, 2012.

35. Tjiu JW, Chen JS, Shun CT, Lin SJ, Liao YH, Chu CY, Tsai TF, Chiu HC, Dai YS, Inoue H, et al: Tumor-associated macrophage-induced invasion and angiogenesis of human basal cell carcinoma cells by cyclooxygenase-2 induction. J Invest Dermatol 129: 1016-1025, 2009.

36. Balkwill F, Charles KA and Mantovani A: Smoldering and polarized inflammation in the initiation and promotion of malignant disease. Cancer Cell 7: 211-217, 2005.

37. Daigneault M, Preston JA, Marriott HM, Whyte MK and Dockrell DH: The identification of markers of macrophage differentiation in PMA-stimulated THP-1 cells and monocyte-derived macrophages. PLoS One 5: e8668, 2010.

38. Konstantinov SR, Kuipers EJ and Peppelenbosch MP: Functional genomic analyses of the gut microbiota for CRC screening. Nat Rev Gastroenterol Hepatol 10: 741-745, 2013.

39. Maddocks OD, Short AJ, Donnenberg MS, Bader S and Harrison DJ: Attaching and effacing Escherichia coli downregulate DNA mismatch repair protein in vitro and are associated with colorectal adenocarcinomas in humans. PLoS One 4: e5517, 2009.

40. Risitano R, Currò M, Cirmi S, Ferlazzo N, Campiglia P, Caccamo D, Ientile R and Navarra M: Flavonoid fraction of bergamot juice reduces LPS-induced inflammatory response through SIRT1-mediated NF- $\kappa$ B inhibition in THP-1 monocytes. PLoS One 9: e107431, 2014.

41. Sunahori K, Yamamura M, Yamana J, Takasugi K, Kawashima M, Yamamoto H, Chazin WJ, Nakatani Y, Yui S and Makino H: The S100A8/A9 heterodimer amplifies proinflammatory cytokine production by macrophages via activation of nuclear factor kappa B and p38 mitogen-activated protein kinase in rheumatoid arthritis. Arthritis Res Ther 8: R69, 2006.

42. XuX,ChenH,Zhu X,Ma Y,Liu Q,Xue Y,ChuH,Wu W, Wang J and Zou H: S100A9 promotes human lung fibroblast cells activation through receptor for advanced glycation end-product-mediated extracellular-regulated kinase $1 / 2$, mitogen-activated protein-kinase and nuclear factor- $\kappa \mathrm{B}-$ dependent pathways. Clin Exp Immunol 173: 523-535, 2013.
43. Cerezo LA, Remáková M, Tomčik M, Gay S, Neidhart M, Lukanidin E, Pavelka K, Grigorian M, Vencovský J and Šenolt L: The metastasis-associated protein S100A4 promotes the inflammatory response of mononuclear cells via the TLR4 signalling pathway in rheumatoid arthritis. Rheumatology (Oxford) 53: 1520-1526, 2014.

44. Austermann J, Friesenhagen J, Fassl SK, Petersen B, Ortkras T, Burgmann J, Barczyk-Kahlert K, Faist E, Zedler S, Pirr S, et al: Alarmins MRP8 and MRP14 induce stress tolerance in phagocytes under sterile inflammatory conditions. Cell Reports 9: 2112-2123, 2014.

45. O'Connell RM, Taganov KD, Boldin MP, Cheng G and Baltimore D: MicroRNA-155 is induced during the macrophage inflammatory response. Proc Natl Acad Sci USA 104: 1604-1609, 2007.

46. Bertoli G, Cava C and Castiglioni I: MicroRNAs: new biomarkers for diagnosis, prognosis, therapy prediction and therapeutic tools for breast cancer. Theranostics 5: 1122-1143, 2015.

47. Xie K, Ma H, Liang C, Wang C, Qin N, Shen W, Gu Y, Yan C, Zhang K, Dai N, et al: A functional variant in miR-155 regulation region contributes to lung cancer risk and survival. Oncotarget 6 : 42781-42792, 2015.

48. Qu YL, Wang HF, Sun ZQ, Tang Y, Han XN, Yu XB and Liu K: Up-regulated miR-155-5p promotes cell proliferation, invasion and metastasis in colorectal carcinoma. Int J Clin Exp Pathol 8: 6988-6994, 2015.

49. Koch M, Mollenkopf HJ, Klemm U and Meyer TF: Induction of microRNA-155 is TLR- and type IV secretion system-dependent in macrophages and inhibits DNA-damage induced apoptosis. Proc Natl Acad Sci USA 109: E1153-E1162, 2012.

50. Min M, Peng L, Yang Y, Guo M, Wang W and Sun G: MicroRNA-155 is involved in the pathogenesis of ulcerative colitis by targeting FOXO3a. Inflamm Bowel Dis 20: 652-659, 2014.

51. Worm J, Stenvang J, Petri A, Frederiksen KS, Obad S, Elmén J, Hedtjärn M, Straarup EM, Hansen JB and Kauppinen S: Silencing of microRNA-155 in mice during acute inflammatory response leads to derepression of c/ebp Beta and down-regulation of G-CSF. Nucleic Acids Res 37: 5784-5792, 2009.

52. Zhang RN, Zheng B, Li LM, Zhang J, Zhang XH and Wen JK: Tongxinluo inhibits vascular inflammation and neointimal hyperplasia through blockade of the positive feedback loop between miR-155 and TNF- $\alpha$. Am J Physiol Heart Circ Physiol 307: H552-H562, 2014.

53. Bala S, Marcos M, Kodys K, Csak T, Catalano D, Mandrekar P and Szabo G: Up-regulation of microRNA-155 in macrophages contributes to increased tumor necrosis factor $\alpha$ (TNF- $\alpha$ ) production via increased mRNA half-life in alcoholic liver disease. J Biol Chem 286: 1436-1444, 2011.

54. Cardoso AP, Pinto ML, Pinto AT, Oliveira MI, Pinto MT, Gonçalves R, Relvas JB, Figueiredo C, Seruca R, Mantovani A, et al: Macrophages stimulate gastric and colorectal cancer invasion through EGFR Y1086, c-Src, Erk1/2 and Akt phosphorylation and small GTPase activity. Oncogene 33: 2123-2133, 2014.

55. He G, Zhang H, Zhou J, Wang B, Chen Y, Kong Y, Xie X, Wang X, Fei R, Wei L, et al: Peritumoural neutrophils negatively regulate adaptive immunity via the PD-L1/PD-1 signalling pathway in hepatocellular carcinoma. J Exp Clin Cancer Res 34: 141, 2015.

56. Li X, Liu C, Ip BC, Hu KQ, Smith DE, Greenberg AS and Wang XD: Tumor progression locus 2 ablation suppressed hepatocellular carcinoma development by inhibiting hepatic inflammation and steatosis in mice. J Exp Clin Cancer Res 34: $138,2015$.

57. 57. Kim JH, Oh SH, Kim EJ, Park SJ, Hong SP, Cheon JH, Kim TI and Kim WH: The role of myofibroblasts in upregulation of S100A8 and S100A9 and the differentiation of myeloid cells in the colorectal cancer microenvironment. Biochem Biophys Res Commun 423: 60-66, 2012.

58. Coffelt SB, Kersten K, Doornebal CW, Weiden J, Vrijland K, Hau CS, Verstegen NJ, Ciampricotti M, Hawinkels LJ, Jonkers J, et al: IL-17-producing $\gamma \delta \mathrm{T}$ cells and neutrophils conspire to promote breast cancer metastasis. Nature 522: 345-348, 2015 